\title{
A 3-month double-blind randomised study comparing an olive oil- with a soyabean oil-based intravenous lipid emulsion in home parenteral nutrition patients
}

\author{
K. Vahedi ${ }^{1}$, P. Atlan ${ }^{2}$, F. Joly ${ }^{1}$, A. Le Brun ${ }^{2}$, D. Evard ${ }^{2}$, V. Perennec ${ }^{2}$, D. Roux-Haguenau ${ }^{3}$, G. Bereziat ${ }^{4}$ \\ and B. Messing ${ }^{1}$ \\ ${ }^{1}$ Department of Gastroenterology and Nutritional Support, Lariboisière University Hospital, 2 rue Ambroise Paré, 75475 Paris Cedex 10, \\ France \\ ${ }^{2} R \& D$ Nutrition, Baxter SAS, 6 avenue Louis-Pasteur, B.P. 56, 783116 avenue Louis-Pasteur, France \\ ${ }^{3}$ Department of Pharmacy, Lariboisière University Hospital, 75010 Paris, France \\ ${ }^{4}$ Laboratory of Biochemistry, Saint-Antoine University Hospital, 75012 Paris, France
}

(Received 29 November 2004 - Revised 16 June 2005 - Accepted 16 June 2005)

\begin{abstract}
Intravenous lipid emulsions (ILE) have demonstrated advantages including prevention of essential fatty acid (EFA) deficiency; however, too much EFA can down regulate fatty acid elongation leading to an imbalance of nutritional compounds in plasma and cell membranes. An olive oil-based ILE containing long-chain triacylglycerols (LCT) with a low content (20\%) of PUFA was administered for home parenteral nutrition (HPN) and compared with a conventional soyabean oil-based ILE (PUFA content, 60\%). Thirteen patients (26-92 years) with stable intestinal failure were randomised after a 1-month run-in period with a medium-chain triacylglycerols-LCT-based ILE, to receive 3 months of HPN with either olive oil- $(n$ 6) or soyabean oil-based ( $n$ 7) ILE. The nutritional impact and safety of HPN, oral intakes and absorption rates, phospholipid fatty acids in plasma and lymphocyte cell membrane were assessed. The only clinical event reported was one case of pneumonia (soya group). In both groups, 20:3n-9:20:4n-6 ratios remained within normal ranges (0.030.07). There was a significant increase of $\gamma$-linolenic acid $(\gamma$-LA) in plasma and lymphocyte cell membrane $(P=0 \cdot 02)$ and of oleic acid in plasma $(P<0 \cdot 01)$ in the olive compared with the soya group. A significant correlation was found between $\gamma$-LA (day 90 - day 0 ) in plasma and PUFA parenteral intakes $(P=0.02)$, but neither with fat intakes nor with fat absorption rates. In conclusion, plasma and lymphocyte EFA pattern remained in normal ranges without EFA deficiency with both lipid emulsions, despite a lower content of $n-3$ and $n-6$ series with the olive oil-based ILE.
\end{abstract}

Home parenteral nutrition: Intestinal failure: Intravenous lipid emulsions: Olive oil

Home parenteral nutrition (HPN) is a therapy for transient or permanent intestinal failure (Jeejeebhoy et al. 1973; Jarnum \& Ladefoged, 1981). Intravenous lipid emulsions (ILE) are an important component of nutritional support, providing energy and preventing essential fatty acid (EFA) deficiency (Koretz et al. 2001). Most currently marketed ILE contain triacylglycerols from soyabean oil sources. New generations of ILE tend to substitute soyabean oil with other sources of fat in order to decrease the content in $n$-6 PUFA (Adolph, 1999). It was suggested that ILE with a high linoleic acid (LA; $18: 2 n-6)$ content could impair the immune and inflammatory status of parenterally fed patients leading to a deleterious outcome (Wan et al. 1988; Kinsella et al. 1990; Fürst, 1998). It has also been shown that feeding a patient with an excessive supply of LA may be accountable for an imbalance of production of eicosanoids (Friedman \& Frolich, 1979; Hageman et al. 1983). An olive oil-based ILE (ClinOleic ${ }^{\circledR} 20 \%$;
Baxter SAS, Maurepas, France) has been registered through the European Community since 1997. It is prepared from a mixture of olive and soyabean oils, containing long-chain triacylglycerols (LCT) with a lower proportion (20\%) of PUFA in comparison with standard soyabean ILE $(60 \%)$. The potential advantages of an olive oil-based ILE rely on its high MUFA content $(60 \%)$ which preserves the immune function (Yaqoob, 2002). Furthermore, olive oil-based ILE has been previously demonstrated to lead to a decreased synthesis of eicosanoids ( $n-6$ series) in healthy volunteers (Dutot et al. 1998) and lipid peroxidation-induced compounds in paediatric HPN patients (Goulet et al. 1999). The design of the last study was comparable with ours. The aim of the present prospective double-blind study was to compare the clinical and metabolic effects of olive oil-based ILE with a standard soyabeanbased ILE (Ivelip ${ }^{\circledR} 20 \%$; Baxter) administered to HPN-dependent adult patients over a 3 -month period. 


\section{Methods}

The protocol was approved by the Committee of Human Rights in Research of Saint-Louis Hospital in Paris and was in accordance with regulations of European Good Clinical Practice.

\section{Patients and study design}

Patients who had been dependent on HPN for more than 6 months and still requiring at least 4 months of non-exclusive HPN were enrolled in the present study after they gave their informed consent. Exclusion criteria were: (a) a malignant or AIDS-related intestinal failure; (b) organ (other than intestinal) failures (renal, respiratory, heart, liver); (c) diabetes mellitus type 1 or 2; (d) infectious complications (systemic or catheter-related) during the previous month; (e) a surgical treatment within the last 3 months; (f) total alkaline phosphatase concentrations more than five times the upper limit of normal value (ULN), aspartate aminotransferase and/or alanine aminotransferase more than three times the ULN, factor V less than $50 \%$, platelet count less than $150000 / \mathrm{mm}^{3}$; (g) biological evidence of inflammation and/or sepsis (i.e. a C-reactive protein concentration above $15 \mathrm{mg} / \mathrm{l}$ ); (h) current treatment with corticosteroids, non-steroid anti-inflammatory or immune-suppressive drugs; (i) alternative treatments for intestinal failure other than HPN (growth hormone, surgically reversed small-bowel loop). Patients were enrolled according to the centre's capacity for recruitment (fifteen to thirty new cases annually). It was planned to include at least twelve patients in the study. The randomisation list based on a blocking method was prepared by a third party independent of the clinical and statistical staff involved in the study. Although patients' enrolment was the responsibility of the physician, the treatment assignment was carried out by the hospital pharmacist using numbered sealed envelopes.

\section{Parenteral nutrition}

All enrolled patients received a run-in period of $30 \mathrm{~d}$ (day -30 to day 0) with a medium-chain triacylglycerol-LCT (50:50, w/w) ILE (Medialipid ${ }^{\circledR}$; B-Braun, Erlangen, Germany) to standardise HPN and minimise fatty acid profile changes possibly induced by previously prescribed ILE (Dahlan et al. 1992; Martin-Pena et al. 2002). For the comparative study period (day 0 to day 90), patients were randomly assigned to receive HPN either with ClinOleic ${ }^{\circledR} 20 \%$ (olive group) or Ivelip ${ }^{\circledR} 20 \%$ (soya group). The constituents of the two ILE are shown in Table 1. Cyclic nocturnal HPN was administered for $12-14 \mathrm{~h}$ overnight via a central catheter (median 5 (range 4-7) times per week). The HPN admixtures were prepared in blinded plastic bags once per week by the hospital pharmacist and then delivered to the patients at home. $\mathrm{N}$, dextrose, vitamins, trace elements and electrolytes were prescribed according to individual needs and usual hospital practices. ILE was added to HPN mixture at a dosage of $50 \mathrm{~g}$ lipids 4 to $6 \mathrm{~d}$ per week. In each case, blood samples were taken in the fasting state and at least $8 \mathrm{~h}$ after the HPN admixture was stopped.

\section{Oral intake evaluation}

Patients were requested to maintain their usual oral intake. They also received routinely 1 to $3 \mathrm{~g}$ oral vitamin $\mathrm{E}$ ( $\alpha$-tocopherol) per d. Dietary inquiry was performed as previously described
Table 1. Composition (per $100 \mathrm{ml}$ ) of the two assessed intravenous lipid emulsions (ClinOleic ${ }^{\circledR} 20 \%$ and Ivelip ${ }^{\circledR} 20 \%$ ), together with the composition of the emulsion used in the run-in period (Medialipid ${ }^{\circledR}$ ) for comparison

\begin{tabular}{lccc}
\hline & $\begin{array}{c}\text { Medialipid } \\
\text { (®) }\end{array}$ & $\begin{array}{c}\text { ClinOleic }^{\circledR} \\
20 \%\end{array}$ & $\begin{array}{c}\text { Ivelip }^{\circledR} \\
20 \%\end{array}$ \\
\hline Soyabean oil (g) & 10 & 4 & 20 \\
Olive oil (g) & 0 & 16 & 0 \\
Medium-chain & 10 & 0 & 0 \\
$\quad$ triacylglycerols (g) & & & \\
Egg phospholipids (g) & 1.2 & 1.2 & 1.2 \\
Glycerol (g) & 2.5 & 2.25 & 2.5 \\
PUFA (\%) & 30 & 20 & 60 \\
MUFA (\%) & 10 & 63 & 23 \\
$n$-6 Fatty acids (\%) & 27 & 18 & 52 \\
Linoleic acid (\%) & 27 & 18 & 52 \\
$\gamma$-Linolenic acid (\%) & $<0.1$ & 2.2 & $<0.1$ \\
$n$-3 Fatty acids (\%) & 3.2 & 2 & 8.2 \\
$\alpha$-Linolenic acid (\%) & 3 & $<0.02$ & 8 \\
EPA (\%) & $<0.02$ & 0.12 & 0.15 \\
DHA (\%) & 0.12 & & \\
\hline
\end{tabular}

(Messing et al. 1991), by a period of three consecutive days at the end of each month during the study period. Intakes were calculated with Bilnut $^{\mathcal{O}}$ software (Bilnut 4.0, SCDA Nutrisoft, Cerelles, France) for total energy, protein, carbohydrates (total, poly- and monosaccharides), fat, alcohol and fibre. The energy-conversion (combustion) factors used were those of Atwater confirmed by Southgate \& Durnin (1970): $17.5 \mathrm{~kJ}$ $(4.2 \mathrm{kcal}) / \mathrm{g}, 39.1 \mathrm{~kJ}(9.3 \mathrm{kcal}) / \mathrm{g}$ and $23.6 \mathrm{~kJ}(5.6 \mathrm{kcal}) / \mathrm{g}$ for carbohydrates, fat and protein, respectively.

\section{Stool analysis and absorption calculation}

Over a $3 \mathrm{~d}$ metabolic period, stools were collected daily. When oral intake was possible, faecal-output analyses were performed on homogenised samples of $3 \mathrm{~d}$ pooled samples as previously published (Messing et al. 1991). In brief, $\mathrm{N}$ and fat were measured by chemiluminescence (Ward et al. 1980) and van de Kamer (van de Kamer et al. 1949) techniques, respectively. The net absorption of protein, fat and energy was calculated by subtracting the amount excreted in faeces from the amount ingested.

\section{Clinical and laboratory monitoring}

All patients were monitored for daily HPN intakes, adverse and intercurrent events from the run-in period (day -30) to the end of the treatment period (day 90). Assessment of BMI was done at day 0 and day 90. Routine laboratory values (including glucose, urea, creatinine, albumin, $\mathrm{Na}, \mathrm{K}$, chloride, bicarbonates, blood cell count, platelets, sedimentation rate and C-reactive protein) and plasma lipid profile (including total cholesterol, HDL-cholesterol, LDL-cholesterol, phospholipids, triacylglycerols) were evaluated at day 0,60 and 90 . Liver function tests were measured at day 0, 30, 60 and 90. Liver function test abnormalities were defined as follows: for cholestasis, an increase over 1.5-fold the ULN values, at least for two among the three parameters of conjugated bilirubin, total alkaline phosphatases, $\gamma$-glutamyltranspeptidase; for cytolysis, an increase over twice the ULN values of aspartate aminotransferase and/or alanine aminotransferase, at least twice among the three assessments, without any 
recognised causes such as viral or drug hepatitis and biliary lithiasis (Cavicchi et al. 2000). Hepatobiliary ultrasound was performed at day 0 and day 90 .

\section{Phospholipid fatty acid profiles in plasma and lymphocyte cell} membrane

Blood samples (day 0, 30, 60 and 90) were immediately processed for plasma separation and isolation of lymphocytes per Ficoll gradient and then for lipid extraction. Fatty acids were measured as described previously by Driss et al. (1988) by using GLC on a Carlo Erba chromatograph (Erba and Sciences, Paris, France) equipped with a polar column (Omegawax Supelco Inc., Bellafonte, PA, USA) and a flame ionisation detector and then conserved at $-20^{\circ} \mathrm{C}$ in tubes containing methanol-butylated hydroxytoluene as antioxidant (Driss et al. 1988). Percentage concentrations of each saturated fatty acid, MUFA and PUFA were determined. In addition the ratios $20: 4 n-6: 18: n-6$ (arachidonic acid (AA):LA), and (sum $n-6+18: n-6)$ :LA were calculated as reflecting a measure of $\Delta 6$ - and $\Delta 5$-desaturase and elongase activities. Triene:tetraene (20:3n-9:20:4n-6) and $n-3: n-6$ ratios were established as respective estimates of EFA deficiency (Holman, 1960) and cell membrane fluidity and immune function (Peck, 1994).

\section{Statistical analysis}

The results are expressed as mean values with their standard errors or as medians and ranges. Comparisons between groups were assessed by the Wilcoxon rank sum test for quantitative criteria and by the Fisher exact test for qualitative ones. Correlations were calculated using the Spearman test. Comparisons of the evolution in each group were evaluated by the Wilcoxon signed rank test. Fatty acids were analysed on the per-protocol group to avoid the deviations due to wrong blood sampling conditions (incorrect blood sampling timing in one case and wrong lipid emulsion infused in another case). The other criteria were analysed considering the intention-to-treat group. A $P$ value of $<0.05$ was considered as significant.

\section{Results}

\section{Patients' characteristics}

Patients from olive ( $n$ 6) and soya ( $n$ 7) groups did not differ at day 0 (Tables 2 and 3). Underlying diseases are detailed in Table 3.

\section{Administered parenteral nutrition}

During the treatment period, the average daily amount of lipid, $\mathrm{N}$ and glucose parenterally provided to the patients was similar in both olive and soya groups (Table 4). $n-6$ and $n$-3 EFA intravenous content (g per infusion) were in olive oil 10 and $1 \mathrm{~g}$ and in soya oil 25 and $4 \mathrm{~g}$, respectively. Other medications, including vitamins, trace elements, and electrolytes, were not significantly different between the two groups.

\section{Oral intakes}

In the soya group, two patients with chronic intestinal pseudoobstruction had no oral intakes. Daily total absorbed energy intakes (Table 3) were statistically lower in the soya than in the olive group (51 (SEM 16) v. 127 (SEM 22) kJ/kg per d, respectively; $P=0.008$ )
Table 2. Patients' characteristics at the time of their inclusion into the study* (Mean values with their standard errors)

\begin{tabular}{|c|c|c|c|c|c|}
\hline & \multicolumn{2}{|c|}{$\begin{array}{l}\text { Olive group } \\
\quad(n 6)\end{array}$} & \multicolumn{2}{|c|}{$\begin{array}{l}\text { Soya group } \\
\qquad(n 7)\end{array}$} & \multirow[b]{2}{*}{$P \dagger$} \\
\hline & Mean & SEM & Mean & SEM & \\
\hline Age (years) & 48 & 4 & 53 & 11 & NS \\
\hline Males $(n)$ & & 4 & & 1 & NS \\
\hline Females $(n)$ & & 2 & & 6 & NS \\
\hline $\begin{array}{l}\text { HPN duration before } \\
\text { study (months) }\end{array}$ & 69 & $30 \cdot 4$ & 77 & 25.9 & NS \\
\hline Height (cm) & 165 & 5 & 159 & 4 & NS \\
\hline Weight (kg) & $52 \cdot 1$ & $4 \cdot 7$ & $48 \cdot 1$ & $2 \cdot 0$ & NS \\
\hline \multicolumn{6}{|l|}{ BMl $\left(\mathrm{kg} / \mathrm{m}^{2}\right)$} \\
\hline All subjects & $18 \cdot 9$ & $1 \cdot 2$ & $19 \cdot 1$ & 0.8 & NS \\
\hline Male & $19 \cdot 8$ & $1 \cdot 7$ & $17 \cdot 0$ & - & - \\
\hline Female & $17 \cdot 2$ & 0.5 & 19.5 & 0.8 & - \\
\hline
\end{tabular}

HPN, home parenteral nutrition.

* Comparison between two groups of patients randomised to receive either olive oil- or soyabean oil-based lipid emulsions were made before the comparative study period (day 0).

† Differences are significant when $P \leq 0.05$ (Fisher exact test for sex or Wilcoxon rank sum test for all other parameters).

and net fat absorption rate (\% of oral lipids absorbed) was lower $(P<0.02)$ in the soya than in the olive group (median 19 (range 3-62) v. 43.5 (range 24-97) \%, respectively). Considering patients as a whole, fatty acid supply was distributed as follows: in saturated fatty acids, median 52 (range 32-64) \%; in MUFA, median 34 (range 27-40) \%; in PUFA, median 14 (range 9-41) \%.

\section{Clinical events during comparative treatment period}

Patients in the olive group did not experience any significant clinical adverse events. Within the soya group, an acute pneumonia appeared in one patient 8 weeks after inclusion; recovery occurred with appropriate treatment without perturbation of the study course.

\section{Body mass index and routine biological data}

None of the following parameters had statistically significant differences at day 0: BMI, serum albumin, as plasma lipid profile, haematological indices, and other routine laboratory tests. This lack of difference remained over the time of the study between groups. Erythrocyte sedimentation rate increased significantly in soya $v$. olive groups $(+14$ (SEM 8) v. -3 (SEM 2) $\mathrm{mm}$; $P<0.04$ ). For all other assessed parameters (plasma lipid profile, vitamin $\mathrm{E}$, urea, creatinine, glucose, $\mathrm{Na}, \mathrm{K}$, chloride, bicarbonates and C-reactive protein), evolution from day 0 to day 90 was not statistically different between the two groups.

\section{Liver abnormalities}

One case of cholestasis (soya group) and one case of cytolysis (olive group) existing at baseline disappeared at day 90. One other patient presented a transient combined cytolysis and cholestasis (olive group). Liver function test changes from day 0 to day 90 were not different between groups. Hepatic ultrasound performed on day 0 detected the following abnormalities: olive group, one case of gallbladder lithiasis and one case of gallbladder sludge associated with steatosis, one case of isolated steatosis; 
Table 3. Functional and anatomical intestinal status of patients

\begin{tabular}{|c|c|c|c|c|c|}
\hline Group & $\begin{array}{l}\text { Absorbed oral energy } \\
(\mathrm{kJ} / \mathrm{kg} \text { per } \mathrm{d})\end{array}$ & $\begin{array}{l}\text { Absorbed oral lipids } \\
(\mathrm{kJ} / \mathrm{kg} \text { per } \mathrm{d})\end{array}$ & $\begin{array}{l}\text { Absorbed oral lipids } \\
(\%)^{\star}\end{array}$ & $\begin{array}{l}\text { Cause of intestinal failure: } \\
\text { SBSt }(\mathrm{cm}) \text { or CIPO }\end{array}$ & Type of anastomosis \\
\hline \multirow[t]{6}{*}{ Olive } & $83 \cdot 6$ & $25 \cdot 9$ & 41 & SBS (60) & End enterostomy \\
\hline & $73 \cdot 1$ & $28 \cdot 8$ & 46 & SBS $(0)$ & Duodenocolic (RC) \\
\hline & $185 \cdot 6$ & $58 \cdot 5$ & 66 & SBS (5) & Jejunocolic (TC) \\
\hline & $102 \cdot 4$ & $23 \cdot 0$ & 34 & SBS (35) & Jejunocolic (LC) \\
\hline & $206 \cdot 1$ & 93.6 & 97 & SBS (120) & Jejunocolic (LC) \\
\hline & $115 \cdot 4$ & $20 \cdot 1$ & 24 & SBS (80) & Jejunocolic (TC) \\
\hline \multirow[t]{7}{*}{ Soya } & $75 \cdot 6$ & 3.0 & 3 & SBS (20) & Jejunocolic (TC) \\
\hline & $72 \cdot 7$ & $27 \cdot 1$ & 59 & SBS (100) & Jejuno-ileocolic \\
\hline & $61 \cdot 8$ & $14 \cdot 2$ & 19 & SBS (40) & Jejunocolic (RC) \\
\hline & ND & $4 \cdot 6$ & 15 & SBS (80) & Jejuno-ileocolic \\
\hline & $96 \cdot 5$ & $32 \cdot 6$ & 63 & CIPO & No surgery \\
\hline & No oral intake & - & 0 & CIPO & Ileorectal \\
\hline & No oral intake & - & 0 & CIPO & No surgery \\
\hline
\end{tabular}

SBS, short-bowel syndrome; CIPO, chronic intestinal pseudo-obstruction; RC, right colon; TC, transverse colon; LC, left colon; ND, not determined.

* Percentage of oral lipids absorbed is calculated as the ratio of net absorption of fat (subtracting the amount excreted in faeces from the amount ingested)/daily oral fat intakes.

† SBS due to multiple bowel resections for familial polyposis $(n 1)$, common mesenter $(n 2)$, arterial mesenteric infarction $(n 4)$, Crohn's disease $(n 1)$ or radiation enteritis $(n 2)$, with a median post-duodenal remnant small-bowel length of 47 (range $5-120) \mathrm{cm}$ in the olive group, and of 60 (range 20-100) cm in the soya group.

soya group, three cases of isolated steatosis. Hepatic ultrasound performed on day 90 detected no hepato-biliary changes compared with the baseline. None of the two patients with gallbladder lithiasis had biliary tract complications during the study.

\section{Phospholipid fatty acid profiles in plasma and lymphocyte cell membrane}

Plasma and lymphocyte fatty acids at baseline were not statistically different between the two groups. In plasma (Table 5), fatty acid evolution from day 0 to day 90 was statistically different between the groups with an increased percentage in olive $v$. soya groups for oleic acid (18:1n-9), $\gamma$-linolenic acid $(\gamma$-LA;

Table 4. Parenteral intakes during the comparative study period (Mean values with their standard errors)

\begin{tabular}{|c|c|c|c|c|c|}
\hline & \multicolumn{2}{|c|}{$\begin{array}{l}\text { Olive group } \\
\quad(n 6)\end{array}$} & \multicolumn{2}{|c|}{$\begin{array}{l}\text { Soya group } \\
(n 7)\end{array}$} & \multirow[b]{2}{*}{$P^{*}$} \\
\hline & Mean & SEM & Mean & SEM & \\
\hline Treatment duration (d) & 84 & 3 & 81 & 3 & NS \\
\hline $\begin{array}{l}\text { Number of patients } \\
\text { with four lipid infusions } \\
\text { per week }\end{array}$ & & 4 & & 4 & NS \\
\hline $\begin{array}{l}\text { Number of patients } \\
\text { with five lipid infusions } \\
\text { per week }\end{array}$ & & 0 & & 3 & NS \\
\hline $\begin{array}{l}\text { Number of patients } \\
\text { with six lipid infusions } \\
\text { per week }\end{array}$ & & 2 & & 0 & NS \\
\hline Lipids (g/kg per d) & 0.7 & 0.1 & 0.7 & 0.0 & NS \\
\hline Lipids (g/kg per infusion) & $1 \cdot 0$ & 0.1 & $1 \cdot 0$ & 0.0 & NS \\
\hline$N(g / k g$ per $d)$ & 0.17 & 0.0 & 0.15 & 0.0 & NS \\
\hline Glucose (g/kg per d) & $3 \cdot 7$ & 0.4 & $4 \cdot 2$ & 0.5 & NS \\
\hline $\begin{array}{l}\text { Non-protein energy } \\
(\mathrm{kJ} / \mathrm{kg} \text { per } \mathrm{d})\end{array}$ & $87 \cdot 3$ & $8 \cdot 3$ & $94 \cdot 8$ & $8 \cdot 3$ & NS \\
\hline Total energy (kJ/kg per d) & 104.9 & $8 \cdot 7$ & $110 \cdot 7$ & $8 \cdot 3$ & NS \\
\hline $\begin{array}{l}\text { Lipids (\% of non-protein } \\
\text { energy) }\end{array}$ & 28.9 & $2 \cdot 3$ & $27 \cdot 9$ & $3 \cdot 3$ & NS \\
\hline $\begin{array}{l}\text { Glucose (\% of non-protein } \\
\text { energy) }\end{array}$ & $71 \cdot 1$ & $2 \cdot 3$ & $72 \cdot 1$ & $3 \cdot 3$ & NS \\
\hline
\end{tabular}

*All differences between groups were NS ( $P>0.05$; Wilcoxon rank sum test).
$18: 3 n-6)$ and Mead's acid (20:3n-9). The triene:tetraene ratio $(20: 3 n-9: 20: 4 n-6)$ remained lower than 0.2 in all patients. Intra-individually, plasma $\gamma$-LA tended to increase in the olive group $(P=0.06 ; \mathrm{NS})$ and to decrease in the soya group $(P=0.09$; NS). The difference of $\gamma$-LA evolution between the two groups observed in plasma was also significant in lymphocytes $(P=0.02$; Table 6$)$. In lymphocytes, intra-individual evolution (day 90 to day 0 ) of $\gamma$-LA was significantly decreased in the soya group $(P=0.03)$ while unchanged in the olive group $(P=0 \cdot 45)$.

A significant correlation between patient's daily parenteral intake of LA and intra-individual evolution (day 90 to day 0 ) of $\gamma$-LA was found in plasma $(P=0.009$; Spearman's correlation coefficient), with a non-significant trend in lymphocytes $(P=0 \cdot 13)$. No significant correlation between oral absorbed intakes of PUFA and changes of $\gamma$-LA was observed in plasma or lymphocytes $(P=0.39$ and $P=0 \cdot 57$, respectively).

\section{Discussion}

The present study confirms, as previously shown in HPN children (Goulet et al. 1999), that the olive oil-based ILE (ClinOleic ${ }^{\circledR}$ ) has a similar nutritional efficacy to a standard soyabean-based ILE $\left(\right.$ Ivelip ${ }^{\circledR}$ ). We used ILE according to the current recommendation of a dose $\leq 1 \mathrm{~g} / \mathrm{kg} \times 4-6 \mathrm{~d} /$ week in patients with intestinal failure (Cavicchi et al. 2000), which corresponded to $30 \%$ of patient's parenteral non-protein energy intake. Although LA content is much lower in olive than in soyabean oil-based ILE, no deficiency in EFA was observed during the study period, as confirmed in both plasma and cell membrane by a triene:tetraene ratio which remained stable and below the threshold of 0.2 in all patients of both groups. It has been reported that more than $25 \%$ of patients with malabsorption have biochemical evidence of EFA deficiency (Farkkila et al. 1987; Siguel \& Lerman, 1996) as well as in patients with short-bowel syndrome (Edes et al. 1991; Chambrier et al. 2002) or under long-term HPN (Abushufa et al. 1995; Mascioli et al. 1996). Conversely, the present findings indicate that a supply of LA corresponding to $18 \%$ of the total parenteral fatty acid intake in the olive group was sufficient to maintain a normal EFA status in patients on long- 
Olive oil and home parenteral nutrition

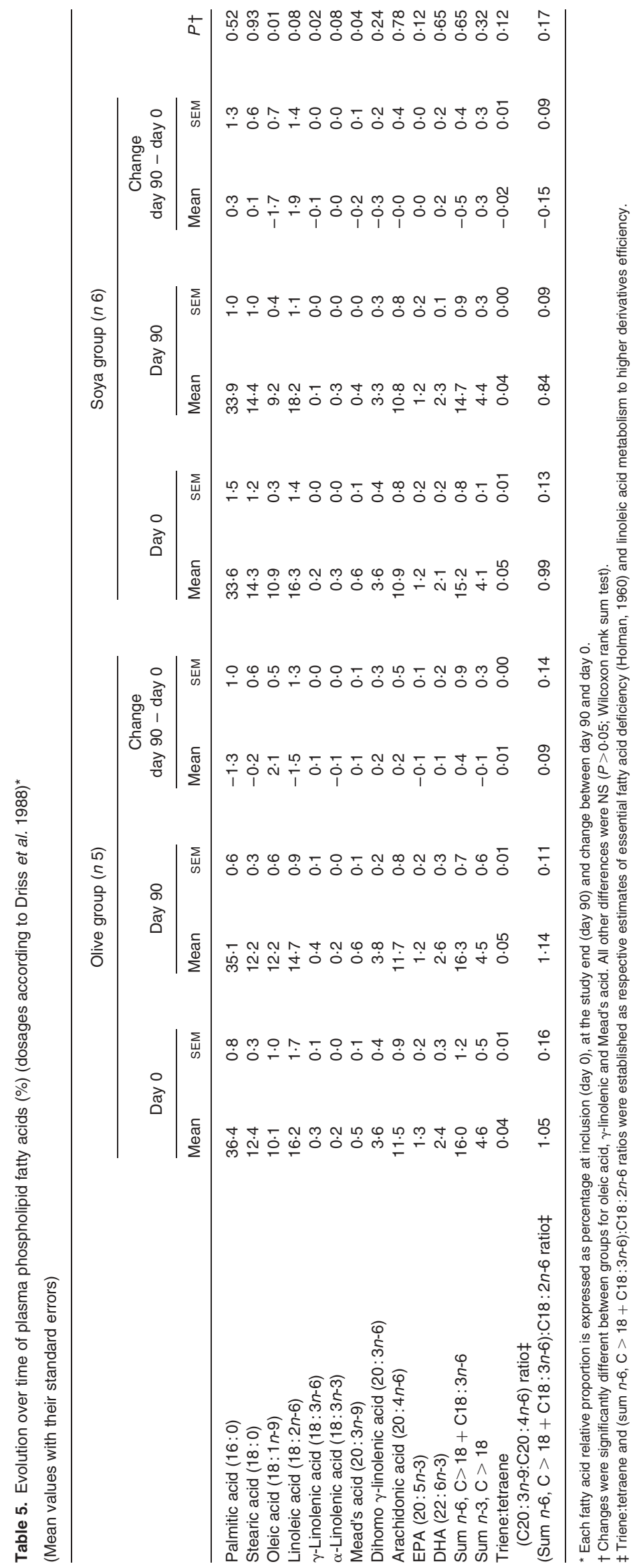


Table 6. Evolution over time of phospholipid fatty acids (\%) in isolated lymphocyte membranes (dosages according to Driss et al. 1988)*

\begin{tabular}{|c|c|c|c|c|c|c|c|c|c|c|c|c|c|}
\hline & \multicolumn{6}{|c|}{ Olive group ( $n 5$ ) } & \multicolumn{6}{|c|}{ Soya group $(n 6)$} & \multirow[b]{3}{*}{$P \dagger$} \\
\hline & \multicolumn{2}{|c|}{ Day 0} & \multicolumn{2}{|c|}{ Day 90} & \multicolumn{2}{|c|}{$\begin{array}{c}\text { Change } \\
\text { day } 90 \text { - day } 0\end{array}$} & \multicolumn{2}{|c|}{ Day 0} & \multicolumn{2}{|c|}{ Day 90} & \multicolumn{2}{|c|}{$\begin{array}{c}\text { Change } \\
\text { day } 90-\text { day } 0\end{array}$} & \\
\hline & Mean & SEM & Mean & SEM & Mean & SEM & Mean & SEM & Mean & SEM & Mean & SEM & \\
\hline Palmitic acid $(16: 0)$ & $22 \cdot 0$ & $2 \cdot 7$ & $23 \cdot 6$ & $2 \cdot 0$ & 1.6 & 4.5 & $18 \cdot 6$ & 2.9 & $22 \cdot 8$ & 1.4 & $4 \cdot 1$ & $4 \cdot 1$ & 0.65 \\
\hline Stearic acid $(18: 0)$ & $20 \cdot 3$ & $1 \cdot 2$ & $21 \cdot 4$ & 1.6 & 1.0 & $2 \cdot 7$ & $22 \cdot 1$ & 0.9 & $21 \cdot 1$ & 0.8 & $-1 \cdot 1$ & $1 \cdot 2$ & 0.78 \\
\hline Linoleic acid $(18: 2 n-6)$ & $8 \cdot 79$ & 0.9 & 8.6 & 1.0 & -0.2 & 1.7 & $8 \cdot 7$ & 0.7 & $9 \cdot 6$ & 0.7 & 0.9 & 0.6 & 0.41 \\
\hline$\gamma$-Linolenic acid $(18: 3 n-6)$ & 0.2 & 0.06 & 0.3 & 0.2 & 0.2 & 0.2 & 0.4 & 0.1 & 0.2 & 0.1 & -0.3 & 0.1 & 0.02 \\
\hline$\alpha$-Linolenic acid $(18: 3 n-3)$ & 0.2 & 0.1 & 0.6 & 0.4 & 0.4 & 0.3 & 0.3 & 0.1 & 0.4 & 0.2 & 0.2 & 0.1 & 0.78 \\
\hline Mead's acid $(20: 3 n-9)$ & 0.7 & 0.1 & 0.5 & 0.1 & -0.2 & 0.2 & 0.9 & 0.1 & 0.8 & 0.1 & $-0 \cdot 1$ & 0.1 & 0.71 \\
\hline $\begin{array}{l}\text { Dihomo } \gamma \text {-linolenic acid } \\
\quad(20: 3 n-6)\end{array}$ & $2 \cdot 2$ & 0.2 & $2 \cdot 1$ & 0.3 & -0.2 & 0.4 & $2 \cdot 3$ & 0.2 & 1.9 & 0.2 & -0.4 & 0.2 & 0.52 \\
\hline Arachidonic acid $(20: 4 n-6)$ & $20 \cdot 9$ & $2 \cdot 7$ & $16 \cdot 9$ & $1 \cdot 6$ & $-4 \cdot 1$ & $3 \cdot 2$ & $21 \cdot 4$ & 1.9 & $18 \cdot 6$ & 1.0 & $-2 \cdot 8$ & $2 \cdot 8$ & 0.65 \\
\hline EPA $(20: 5 n-3)$ & 0.6 & 0.1 & 0.9 & 0.2 & 0.3 & 0.2 & 0.4 & 0.1 & 0.8 & 0.1 & 0.4 & 0.1 & 0.78 \\
\hline Sum $n-3, C>18$ & $4 \cdot 3$ & 0.5 & $4 \cdot 0$ & 0.5 & -0.3 & 0.9 & $4 \cdot 1$ & 0.5 & 3.49 & 0.42 & -0.6 & 0.8 & 1.00 \\
\hline $\begin{array}{l}\text { Triene:tetraene } \\
\qquad(\mathrm{C} 20: 3 n-9: \mathrm{C} 20: 4 n-6) \text { ratio } \ddagger\end{array}$ & 0.04 & 0.00 & 0.03 & 0.01 & -0.01 & 0.01 & 0.04 & 0.01 & 0.04 & 0.00 & 0.00 & 0.01 & 0.78 \\
\hline $\begin{array}{l}\text { (Sum } n-6, C>18+\text { C18: } 3 n-6) \\
\quad \text { C18: } 2 n-6 \text { ratio } \neq\end{array}$ & $3 \cdot 2$ & 0.71 & $2 \cdot 52$ & 0.20 & $-0 \cdot 70$ & 0.79 & 3.23 & 0.46 & $2 \cdot 38$ & 0.08 & -0.85 & 0.42 & 0.93 \\
\hline
\end{tabular}

* Each fatty acid relative proportion is expressed as percentage at inclusion (day 0), at the study end (day 90) and change between day 90 and day 0.

† Changes were significantly different $(P<0.05)$ between groups for all fatty acids except for $\gamma$-linolenic acid (Wilcoxon rank sum test).

¥ Triene:tetraene and (sum $n-6, C>18+C 18: 3 n-6): C 18: 2 n-6$ ratios were established as respective estimates of essential fatty acid deficiency (Holman, 1960) and linoleic acid metabolism to higher derivatives efficiency.

term HPN. The present study design seems appropriate to observe changes in eicosanoids, since the depletion in EFA has been shown to occur within 5 weeks in seven adult patients receiving fat-free total parenteral nutrition, with correction of EFA deficiency within 2 weeks in three patients after resumption of oral feeding (Fleming et al. 1976). Moreover, dietary supplementation with $n$-3 PUFA (18 g fish oil concentrate) for 6 weeks was shown to inhibit the production of IL-1 and TNF, together with a decreased AA:eicosapentaenoic acid ratio in the membrane phospholipids of mononuclear cells in healthy volunteers; 20 weeks after the end of $n-3$ supplementation, the production of these pro-inflammatory mediators had returned to the pre-supplement level (Endres et al. 1989).

Relationships between PUFA intakes, PUFA membrane content and immune and inflammatory responses have been clearly established. An excess of PUFA can inhibit the first steps of elongation of EFA, the ensuing production of eicosanoids, and can reduce cell membrane resistance to oxidative stress (Kinsella et al. 1990). According to this, it is not recommended that the daily intake of PUFA exceeds $10 \%$ of the total energy intake in the normal diet (Committee on Diet, Nutrition, and Cancer, 1982; Eristland, 2000). For patients parenterally fed, it has been shown that a supply of LA of $13 \%$ or more of the total energy intake inhibits $\Delta-6$ desaturase (Pironi et al. 1993), whose key role is to control the first step of conversion of LA to $\gamma$-LA. In the present study, after the 1-month run-in period, parenteral intakes in energy and protein remained unchanged and similar in the two groups but LA parenteral intake increased $200 \%$ with Ivelip ${ }^{\circledR}$ and decreased $30 \%$ with ClinOleic ${ }^{\circledR}$. Then, the total daily supply of PUFA (oral absorbed + parenteral) represented 5.7 (SEM 0.3) \% of the total energy intake in patients receiving the olive oil-based ILE and 14.8 (SEM 2.2) \% in patients receiving the soyabean oil-based ILE. This is consistent with the finding that LA parenteral intake was inversely correlated with $\gamma$ LA changes in plasma, with a significantly higher $\gamma$-LA in plasma and lymphocytes in the olive than in the soya group. We found no difference between the groups on AA changes when compared with baseline. Although oral absorbed intake was lower in the soya group than in the olive group, due to the fact that two patients out of a total of six had no oral intakes in the soya group, a similar evolution in the status of $\gamma$-LA and AA would have been expected. Indeed, nutritional, hormonal and biochemical studies (Cho et al. 1999) have showed that $\Delta-5$ desaturase responsible for the desaturation of $20: 3 n-6$ may be regulated by $\Delta-6$ desaturase. These apparently contradictory findings could be explained by the fact that AA not only results from LA metabolism, but is also present in food in significant concentrations (Gurr, 1984).

The other differences found in plasma and cell fatty acids can be explained by the different composition of the two ILE. It is noticeable that conversely to changes in plasma, oleic acid content has not been significantly modified in the lymphocyte cell membranes; this observation remains compatible with the relative neutrality observed with oral MUFA on human cell membranes (Yaqoob, 2002).

The increase of 20:3n-9 (n-9 eicosatrienoic acid; i.e. Mead's acid) within the olive group probably results from the same explanation. Mead's acid is normally present in cell membranes in very low concentrations and its relative increase is sometimes interpreted as a consequence of an EFA deficiency. This fatty acid is nevertheless endogenously synthesised after dietary intakes and metabolisation of oleic acid, as a homologue of AA and EPA. Besides, several experimental studies have demonstrated that incorporation of Mead's acid in the diet confers anti-inflammatory benefits 
(Yoshida et al. 2003) linked to the inhibition of eicosanoids, including leucotriene B4 synthesis (James et al. 1993). In lymphocyte membrane, the only statistically significant difference found between groups was an increase of $\gamma$-LA in the olive group contrasting with a decrease in the soya group. This observation indicates that a 3-month HPN duration can influence lymphocyte cell-membrane composition and consequently its structure and function. EFA profiles ( $n-6$ and $n-3)$ were comparable with both emulsions with the exception of $\gamma$-LA, despite the fact that intravenous provision of LA and $\alpha$-linolenic acid were respectively 3 - and 4-fold less in the Clinoleic ${ }^{\circledR}$ than in the Ivelip ${ }^{\circledR}$ group.

Long-term HPN with $n$-6-rich-LCT ILE is known to be associated with hepatobiliary dysfunction and haematological abnormalities (Cavicchi et al. 2000). No impact on liver and global safety and clinical outcome was noticed over this 3-month study period. Although it cannot be ruled out that a period of 3 months remained too short to reveal a clinical or laboratory advantage linked to the source of infused lipid, these unchanged liver function tests associated with a stable nutritional status in all patients can be explained by a moderate fat intake, i.e. $\leq 1 \mathrm{~g} / \mathrm{kg}$ per $\mathrm{d}$. A time-limited duration of nutritional intervention assessed during clinical trials could then explain the difficulty of showing its impact (Yaqoob et al. 1998). With respect to this, HPN represented a situation where the effects of a qualitative change in the HPN formula, such as the use of a new lipid emulsion, induced noticeable biological changes. The $\gamma$-LA changes raise the concern of ILE tolerance in longer-term HPN. Indeed, in a recently reported trial according to a prospective but not comparative design, assessing a 6-month period with ClinOleic ${ }^{\circledR}$ in HPN adults, fewer thrombotic episodes where found when compared with recorded events during the two 6-month periods before and after the trial where all patients were treated with a conventional soyabean-based ILE (Thomas-Gibson et al. 2004).

In conclusion, the present study confirms that HPN can be efficiently and safely administered on a long-term basis in adult patients with intestinal failure, provided that its fat supply remains under $1 \mathrm{~g} / \mathrm{kg}$ per $\mathrm{d}$. In such settings, HPN allows the patient to maintain nutritional status and prevents an EFA deficiency without inducing abnormalities on haematology and liver function. ClinOleic $^{\circledR}$, an ILE providing a moderate PUFA supply $(20 \%$ total fatty acids) has demonstrated a better preservation of the biosynthesis pathway of the $n-6$ PUFA than a soyabean oil-based ILE containing higher levels of PUFA ( $60 \%$ total fatty acids). It is therefore noteworthy that no EFA deficiency was observed with intravenous intake representing 6 and $0.5 \%$ of non-protein energy input for LA and $\alpha$-linolenic acid in the olive-oil group, respectively. In the present study, a change of parenteral lipid intakes during a 3-month period was shown to be able to modify the composition of lymphocyte membranes, and presumably their function, in intestinal failure patients on HPN whatever their oral intake.

\section{Acknowledgements}

We gratefully acknowledge Sophie Penven-Rousseau and MarieChristine Morin, dietitians, for their collaboration and outstanding work. The present study was supported by a grant from Baxter S.A.S., 78311 Maurepas, France and presented in an abstract form at the 21st ESPEN Congress, Stockholm, Sweden, September 1999 (Uahedi et al. 1999).

\section{References}

Abushufa R, Reed P, Weeinkove C, Wales S \& Shaffer J (1995) Essential fatty acid status in patients on long-term home parenteral nutrition. J Parenter Enter Nutr 19, 286-290.

Adolph M (1999) Lipid emulsions in parenteral nutrition. Ann Nutr Metab 43, $1-13$.

Cavicchi M, Beau P, Crenn P, Degott C \& Messing B (2000) Prevalence of liver disease and contributing factors in patients receiving home parenteral nutrition for permanent intestinal failure. Ann Intern Med $\mathbf{1 3 2}$ $525-532$.

Chambrier C, Garcia I, Bannier E, Gerard-Boncompain M \& Boulétreau P (2002) Specific changes in $n-6$ fatty acid metabolism in patients with chronic intestinal failure. Clin Nutr 21, 67-72.

Cho HP, Nakamura M \& Clarke SD (1999) Cloning, expression, and fatty acid regulation of the human delta-5 desaturase. J Biol Chem 274, $37335-37339$.

Committee on Diet, Nutrition, and Cancer (1982) Diet, Nutrition, and Cancer. Washington, DC: National Academy Press.

Dahlan W, Richelle M, Kulapongse S, Rössle C, Deckelbaum RJ \& Carpentier YA (1992) Effects of essential fatty acid contents of lipid emulsions on erythrocyte polyunsaturated fatty acid composition in patients on long-term parenteral nutrition. Clin Nutr 11, 262-268.

Driss F, Darcet P, Delhaye N \& Mendy F (1988) Effect of eicopentanoic acid on RBC filterability and fatty acid composition. Clin Hemophil 8, 679-685.

Dutot G, Brouwert CB, Le Brun A, De Bruin TW, Erkelens DW \& Bereziat G (1998) Dose effect response to infusion of linoleic acid on eicosanoids production in healthy volunteers. Clin Nutr 17, Suppl. 1, 58.

Edes TE, Walk BE, Thornton WH \& Fristsche KL (1991) Essential fatty acid sufficiency does not preclude fat-soluble-vitamin deficiency in short bowel syndrome. Am J Clin Nutr 53, 499-502.

Endres S, Ghorbani R, Kelley VE, et al. (1989) The effect of dietary supplementation with $n-3$ polyunsaturated fatty acids on the synthesis of interleukin-1 and tumor necrosis factor by mononuclear cells. $N$ Engl J Med 320, 265-271.

Eristland J (2000) Safety considerations of polyunsaturated fatty acids. Am J Clin Nutr 71, Suppl, 197S-201S.

Farkkila MA, Tilvis RS \& Miettinen TA (1987) Plasma fatty acid composition in patients with ileal dysfunction. Scand J Gastroenterol 22, 411-419.

Fleming CR, Smith LM \& Hodges RE (1976) Essential fatty acid deficiency in adults receiving total parental nutrition. Am J Clin Nutr 29, 976-983.

Friedman Z \& Frolich JC (1979) Essential fatty acids and the major urinary metabolites of the $\mathrm{E}$ prostaglandins in thriving neonates and in infants receiving parenteral fat emulsions. Pediatr Res 13, 932-936.

Fürst P (1998) Old and new substrates in clinical nutrition. J Nutr 128, 789-796.

Goulet O, De Potter S, Antebi H, et al. (1999) Long-term efficacy and safety of a new olive oil-based intravenous fat emulsion in paediatric patients: a double blind randomized study. Am J Clin Nutr 70, 338-345.

Gurr MI (1984) Agricultural aspects of lipids. In The Lipid Handbook, [FD Gunstone, JL Harwood and FB Padley, editors]. London: Chapman and Hall.

Hageman JR, McCulloch K, Gora P, Olsen EK, Pachman L \& Hunt CE (1983) Intralipid alterations in pulmonary prostaglandin metabolism and gas exchange. Crit Care Med 11, 794-798.

Holman RT (1960) The ratio of trienoic:tetraenoic acids in tissue lipids as a measure of essential fatty acid requirement. $J$ Nutr 70, 405-410.

James MJ, Gibson RA, Neumann MA \& Cleland LG (1993) Effect of dietary supplementation with n-9 eicosatrienoic acid on leukotriene B4 synthesis in rats: a novel approach to inhibition of eicosanoid synthesis. J Exp Med 178, 2261-2265.

Jarnum S \& Ladefoged K (1981) European experience of home parenteral nutrition. Acta Chir Scand 507, Suppl., 128-129. 
Jeejeebhoy KN, Zohrab WJ, Langer B, Philips MJ, Kuksis A \& Anderson GH (1973) Total HPN at home for 23 months without complication and with good rehabilitation: a study of technical and metabolic features. Gastroenterology 65, 811-820.

Kinsella JE, Lokesh B, Broughton S \& Whelan J (1990) Dietary polyunsaturated fatty acids and eicosanoids: potential effects on the modulation of inflammatory and immune cells: an overview. Nutrition 6, 24-44.

Koretz RL, Lipman TO \& Klein S, American Gastroenterological Association (2001) AGA technical review on parenteral nutrition. Gastroenterology 121, 970-1001.

Martin-Pena G, Culebras JM, De la Hoz Perales L, Barro-Ordovas JP, CatalaPizarro R \& Ruiz-Galiana J (2002) Effects of 2 lipid emulsions (LCT versus MCT/LCT) on the fatty acid composition of plasma phospholipid: a double-blind randomized trial. J Parenter Enter Nutr 26, 30-41.

Mascioli EA, Lopes SM, Champagne C \& Driscoll DF (1996) Essential fatty acid deficiency and home parenteral nutrition patients. Nutrition 12, 245-249.

Messing B, Pigot F, Rongier M, Morin MC, Ndeindoum U \& Rambaud JC (1991) Intestinal absorption of free oral hyperalimentation in the very short bowel. Gastroenterology 100, 1502-1508.

Peck MD (1994) Interaction of lipids with immune function I: biochemical effects of dietary lipids on plasma membranes. J Nutr Biochem 5, 466-478.

Pironi L, Belluzzi A, Gionchetti P, et al. (1993) Possible role of structural lipids in artificial nutrition: comparison of a linoleic acid-based with an oleic acidbased enteral formula in humans. Clin Nutr 12, Suppl. 1, S91-S96.

Siguel AN \& Lerman RH (1996) Prevalence of essential fatty acid deficiency in patients with chronic gastrointestinal disorders. Metabolism 45, 12-23.
Southgate DAT \& Durnin JVGA (1970) Calorie conversion factors. An experimental reassessment of the factors used in the calculation of the energy value of human diet. Br J Nutr 24, 517-535.

Thomas-Gibson S, Jawhari A, Atlan P, Le Brun A, Farthing M \& Forbes A (2004) Safe and efficacious prolonged use of an olive oil-based lipid emulsion (ClinOleic (C) in chronic intestinal failure. Clin Nutr 23, $697-703$.

Uahedi K, Bereziot G, Lebrun A, Perennec V, Evard D, Atlan P, Dutot G \& Messing B (1999) A randomized double, blinded-3-months study in home parenteral nutrition patients with olive or soy oil-based lipid emulsions: safety, nutritional status, plasma and cell-membrane fatty acid profiles. Clin Nutr 18, Suppl. 1, 48.

van de Kamer JH, Huihink H \& Weyers HA (1949) Rapid method for determination of fat in faeces. J Biol Chem 177, 347-355.

Wan JMF, Teo TC, Babayan VK \& Blackburn GL (1988) Invited comment: lipids and the development of immune dysfunction and infection. J Parenter Enter Nutr 12, Suppl. 6, 43S-52S.

Ward MW, Owens CWI \& Rennie MJ (1980) Nitrogen estimation in biological samples by use of chemiluminescence. Clin Chem 26, $1336-1339$.

Yaqoob P (2002) Monounsaturated fatty acids and immune function. Eur J Clin Nutr 56, Suppl. 3, S9-S13.

Yaqoob P, Knapper JA, Webb DH, Williams CM, Newsholme EA \& Calder PC (1998) Effect of olive oil on immune function in middleaged men. Am J Clin Nutr 76, 129-135.

Yoshida H, Soh H, Sando K, Wasa M, Takagi Y \& Okada A (2003) Beneficial effects of $n-9$ eicosatrienoic acid on experimental bowel lesions. Surg Today 33, 600-605. 